\title{
Tanshinone IIA inhibits BT-20 human breast cancer cell proliferation through increasing caspase 12, GADD153 and phospho-p38 protein expression
}

\author{
MENG-YI YAN $^{1 *}$, SU-YU CHIEN $^{2 *}$, SHOU-JEN KUO $^{1}$, DAR-REN CHEN $^{1,3}$ and CHIN-CHENG SU ${ }^{1,3,4,5}$ \\ ${ }^{1}$ Department of Surgery, ${ }^{2}$ Department of Pharmacy, ${ }^{3}$ Comprehensive Breast Cancer Center, \\ Changhua Christian Hospital, Changhua, Changhua County 50006; ${ }^{4}$ Ming-Dao University, Peetow, \\ Changhua County 52345; ${ }^{5}$ China Medical University, Taichung 40402, Taiwan, R.O.C.
}

Received November 28, 2011; Accepted January 16, 2012

DOI: 10.3892/ijmm.2012.908

\begin{abstract}
Breast cancer is the leading cause of cancer-related deaths in women worldwide. Tanshinone IIA (Tan-IIA) is one of the pure compounds from Salviae miltiorrhizae radix (Danshen). Tan-IIA can inhibit human breast cancer cells but the molecular mechanisms are not well understood. Our previous study showed that Tan-IIA can inhibit hep-J5 human hepatocellular carcinoma cells through the endoplasmic reticulum (ER) stress-induced apoptotic pathway. In the present study, we evaluated the effects of Tan-IIA on BT-20 human breast cancer cells and assessed the involvement of the ER-stress-apoptotic pathway. The cytotoxicity of Tan-IIA in BT-20 cells was measured by the MTT assay. The cell cycles were analyzed by flow cytometry. The expression of ER stress-related proteins in BT-20 cells treated with Tan-IIA were evaluated by western blotting and immunocytochemical staining. These results showed that Tan-IIA can inhibit BT-20 cells and increase the sub-G1 phase in a time- and dose-dependent manner. Tan-IIA could increase the protein expression of caspase 12, GADD153, caspase 3, phospho-JNK, phospho-p38 and Bax, but decreased Bcl-xl and phospho-ERK expression in BT-20 cells. These findings indicate that Tan-IIA possesses therapeutic potential for human breast cancer BT-20 cells; one of the molecular mechanisms may be through inducing ER stress and the MAPK pathway to induce apoptosis and inhibit proliferation.
\end{abstract}

Correspondence to: Dr Chin-Cheng Su, Department of Surgery, Comprehensive Breast Cancer Center, Laboratory of Integrative Medicine Cancer Research, Changhua Christian Hospital, 135 Nan-Hsiao Street, Changhua, Changhua County 50006, Taiwan, R.O.C.

E-mail: succ.maeva@msa.hinet.net

*Contributed equally

Key words: tanshinone IIA, BT-20 cells, endoplasmic reticulum stress, MAPK

\section{Introduction}

Tanshinone IIA (Tan-IIA) is one of the pure compounds from Salviae miltiorrhizae radix (Danshen). It is well documented that Tan-IIA has antioxidant (1-3), and anti-inflammatory properties (4-6). In addition, Tan-IIA could inhibit multiple types of human cancer cells, such as human hepatocellular carcinoma cells (7), human breast cancer (8) and acute promyelocytic leukemia cells (9). Our previous studies have demonstrated that Tan-IIA inhibits the proliferations of human breast cancer MDA-MB-231 cells (10) human colon cancer Colo-205 cells $(11,12)$, small cell lung cancer H146 cells $(13)$, non-small cell lung cancer A549 (14) and human hepatocellular carcinoma hep-J5 cells (15). Breast cancer is the leading cause of cancerrelated death in women worldwide (16). Tan-IIA inhibition of human breast cancer cells is well-documented $(8,17-19)$. However, the molecular mechanisms are not understood clearly. Our previous study showed that Tan-IIA can inhibit human hepatocellular cancer hep-J5 cells through the endoplasmic reticulum (ER) stress-induced apoptotic pathway (14). In the present study, we assessed the effects of Tan-IIA in human breast cancer BT-20 cells and evaluated the involvement of the ER stress pathway and of other pathways in the Tan-IIA effects.

\section{Materials and methods}

Chemicals and reagents. Fetal bovine serum (FBS), sodium pyruvate, HEPES, dimethyl sulfoxide (DMSO), RPMI-1640, MTT, trypsin-EDTA, mouse anti- $\beta$-actin, and penicillinstreptomycin, were obtained from Sigma-Aldrich (St. Louis, MO, USA). Buffer (10X TG-SDS), Tris, Tween-20, SDS and glycine, were obtained from Amresco (St. Louis, MO, USA). BioMax film was obtained from Kodak. The p38 inhibitor, SB203580 and the ERK inhibitor, were obtained from Cell Signaling Technology (Beverly, MA, USA). The caspase inhibitor, ZVAD-FMK was obtained from R\&D Bioscences. Other materials and reagents not specified were obtained from Sigma or Merck.

Cell culture. The human breast cancer BT-20 cells are an estrogen receptor negative human breast cancer cells, obtained 
from the American Type Culture Collection (ATCC, HTB-19). BT-20 was established from a 74 year-old Caucasian female by E.Y. Lasfargues and L. Ozzello in 1958. The BT-20 cells were maintained in RPMI-1640 medium containing 10\% FBS, $1 \%$ penicillin/streptomycin $(10,000 \mathrm{U} / \mathrm{ml}$ penicillin, $10 \mathrm{mg} / \mathrm{ml}$ streptomycin) at $37^{\circ} \mathrm{C}$ in a humidified atmosphere containing $5 \% \mathrm{CO}_{2}(20)$.

Cell proliferation assay. The BT-20 cells were plated in 96-well plates at a density of $1 \times 10^{4}$ cells/well and allowed to adhere and grow for $24 \mathrm{~h}$. The medium was then replaced with $100 \mu \mathrm{l} /$ well of fresh medium containing various concentrations of Tan-IIA $(0,0.25,0.5,1,2,4$ and $8 \mu \mathrm{g} / \mathrm{ml})$ and the cells were cultured for different durations $(24,48$ and $72 \mathrm{~h}$ ). Then, $100 \mu \mathrm{l}$ of $1 \mathrm{mg} / \mathrm{ml}$ MTT (3-(4,5-dimethylthiazol-2-yl)2,5-diphenyl-2H-tetrazolium bromide) were added and then the cells were incubated for $2 \mathrm{~h}$ at $37^{\circ} \mathrm{C}$. Subsequently, the medium was removed and $100 \mu 1 \mathrm{DMSO}$ was added to the wells. The absorbance was measured using an ELISA plate reader at $560 \mathrm{~nm}$. Data were calculated as the percentage of proliferation by using the following formula: proliferation $(\%)=\left(\mathrm{OD}_{\text {test }}-\mathrm{OD}_{\text {blank }}\right) \times 100$, where $\mathrm{OD}_{\text {test }}$ and $\mathrm{OD}_{\text {blank }}$ are the optical densities of the test substances and the blank controls, respectively (15).

Cell cycle analysis. The BT-20 cells were plated in 12-well plates at a density of $6 \times 10^{5}$ cells/well and allowed to adhere and grow for $24 \mathrm{~h}$, then were treated with Tan-IIA $(3 \mu \mathrm{g} / \mathrm{ml})$ for different durations $(24,48$ and $72 \mathrm{~h})$ or treated with various concentrations of Tan-IIA $(0,1.5,3$ and $4.5 \mu \mathrm{g} / \mathrm{ml})$ for $24 \mathrm{~h}$. The cells were harvested and washed with PBS and then resuspended in $70 \%$ ethanol (at $-20^{\circ} \mathrm{C}$ ) overnight. The cells were washed thrice with $2 \mathrm{ml}$ PBS and then stained with $20 \mu \mathrm{g} / \mathrm{ml}$ propidium iodide (PI) buffer $(0.1 \%$ Triton X-100, $0.2 \mu \mathrm{g} / \mathrm{ml}$ RNase A, $40 \mu \mathrm{g} / \mathrm{ml} \mathrm{PI})$. The DNA content was analyzed by fluorescence-activated cell sorting analysis (Beckman Coulter, FC500 flow cytometer) using CXP software (CXP cytometer and CXP analysis) (21).

Protein preparation. Approximately $1.5 \times 10^{6}$ cells/6-cm dish were incubated with Tan-IIA $(3 \mu \mathrm{g} / \mathrm{ml})$ for different durations $(0,1,3,6$ and $24 \mathrm{~h} ; 24,48$ and $72 \mathrm{~h})$ before the cells were harvested by centrifugation. The BT-20 cells were washed twice with ice-cold PBS and lysed in $100 \mu \mathrm{l}$ of lysis buffer (Pro-Prep buffer; Intron). After incubation on ice for $30 \mathrm{~min}$, the cell lysates were centrifuged $\left(13,000 \mathrm{rpm}, 4^{\circ} \mathrm{C}\right.$ for $\left.10 \mathrm{~min}\right)$ and the supernatants were collected. The protein concentration of the samples was determined by the Bradford assay (BioRad, Hercules, CA, USA) (10).

Western blotting. Western blot analysis was conducted using antibodies against calreticulin, caspase 12, cleaved caspase 3, GADD153, Bax, Bcl-xl, p-JNK, JNK, p-p38, p38, p-ERK and ERK. $\beta$-actin was used as the internal control to determine loading efficiency. Protein samples (containing $30 \mu \mathrm{g}$ of protein) were separated on $10-12 \%$ sodium dodecyl sulfatepolacrylamide gel electrophoresis (SDS-PAGE) and transferred to immobilon polyvinylidene difluoride memberane (PVDF) membranes (Millipore, Bedford, MA). The membranes were incubated in TBST buffer [0.1 M Tris- $\mathrm{HCl}(\mathrm{pH} 7.4), 0.9 \%$
$\mathrm{NaCl}, 0.1 \%$ Tween-20] supplemented with 5\% dry non-fat milk for $1 \mathrm{~h}$ to block non-specific binding. After incubation with the primary antibodies, the membranes were washed thrice with TBST buffer followed by incubation with the appropriate streptavidin-HRP-conjugated secondary antibodies. The immunoreactive bands were visualized using an enhanced chemiluminescence detection kit (Millipore). Immunoreactive bands were scanned (2000R; Kodak, Image Station) and analyzed by using ImageJ software (http://rsb.info.nih.gov/ $\mathrm{ij} /$ ) (22). Antibodies for calreticulin (no. 2891; 1:1,000), caspase 12 (no. 2202; 1:1,000), GADD153 (no. 2895; 1:2,000), full length caspase 3 (no. 9662; 1:1,000), phospho-ERK (no. 4730; 1:1,000), total-ERK (no. 9212; 1:1,000), total-JNK (no. 9252; 1:1,000), phospho-p38 (no. 9212; 1:2,000), totalp38 (no. 3491; 1:1,000), Bax (no. 2774; 1:2,000) and Bcl-xl (no. 2764; 1:1,000) were from Cell Signaling Technology. Antibodies for cleaved caspase 3 (no. GTX61024, 1:500) and phospho-JNK (no. GTX24821, 1:1,000) were from GeneTex, Inc.(San Antonio, TX, USA). The antibody for $\beta$-actin was from Sigma (no. A5441; 1:10,000). HRP-conjugated horse anti-mouse and goat anti-rabbit IgG antibodies were obtained from Cell Signaling Technology. Other materials and reagents not specified were obtained from Sigma or Merck.

Immunocytochemical staining. The immunocytochemical analysis procedures have been previously described (6). Briefly, the BT-20 cells were treated with Tan-IIA $(3,6$ and $9 \mu \mathrm{g} / \mathrm{ml})$ for $24 \mathrm{~h}$, and were then fixed with $4 \%$ paraformaldehyde to allow the detection of caspase 12 (Cell Signaling Technology, no. 2202, 1:200), caspase 3 antibodies (GeneTex, Inc., 1:20). No treatment was used as the control, for the detection of the FITC-conjugated secondary antibody (1:500; Chemicon). The cells were then observed under a fluorescent microscope (Olympus, Olympus Model 1X81 microscope system).

Evaluate the effects of p38, ERK and caspase by SB203580, PD98059 and Z-VAD-FMK. BT-20 cells were pretreated with p38 inhibitor $(50 \mu \mathrm{M})$ (SB203580, Cell Signaling Technology, no. 5633), ERK inhibitor (50 $\mu \mathrm{M})$ (PD98059, Cell Signaling Technology, no. 9900), caspase inhibitor (50 $\mu \mathrm{M})$ (ZVAD-FMK, RD, no. FMK001) for $1 \mathrm{~h}$, respectively, then were treated with Tan-IIA ( $3 \mu \mathrm{g} / \mathrm{ml})$ for $24 \mathrm{~h}$. Cell viability was determined by the MTT assay as previously described (23).

Statistical analysis. Values are presented as the means \pm SD. The Student's t-test was used to analyze statistical significance. A P-value $<0.05$ was considered statistically significant for all the tests.

\section{Results and Discussion}

The effects of Tan-IIA on the viability of BT-20 cells. The BT-20 cells were plated in 96-well plates at a density of $1 \times 10^{4}$ cells/well and treated with various concentrations of Tan-IIA $(0,0.25,0.5$, $1,2,4$ and $8 \mu \mathrm{g} / \mathrm{ml})$ for different durations (24, 48 and $72 \mathrm{~h})$ as previously described. The viable cell percentages relative to the control were $98.97 \pm 6.32,99.32 \pm 2.55,81.08 \pm 5.48,53.76 \pm 0.56$, $36.4 \pm 3.89$ and $30.88 \pm 1.2 \%$ respectively, when cultured with $0.25,0.5,1,2,4$ and $8 \mu \mathrm{g} / \mathrm{ml}$ of Tan-IIA for $24 \mathrm{~h}$, respectively. The viable cell percentages relative to the control were 


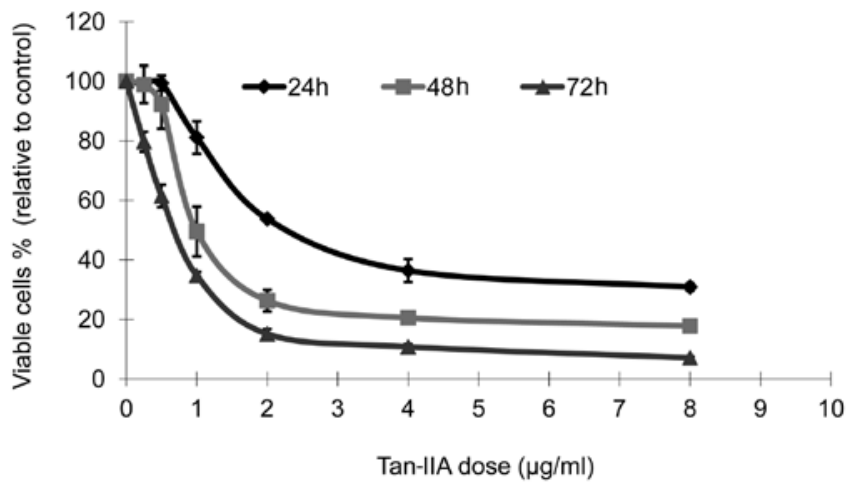

Figure 1. Cytotoxicity of Tan-IIA in BT-20 cells. The cytotoxicity of Tan-IIA in BT-20 cells was determined using the MTT assay as described in Materials and methods. Tan-IIA significantly inhibited BT-20 cell proliferation in a time- and dose-dependent manner. Each point is the mean $\pm \mathrm{SD}$ of three experiments.

A

control

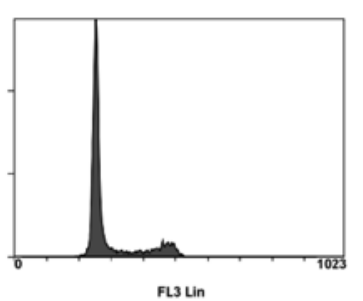

$48 \mathrm{~h}$

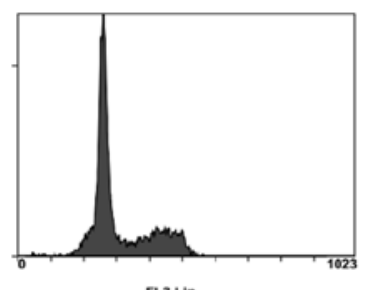

FL3Lin

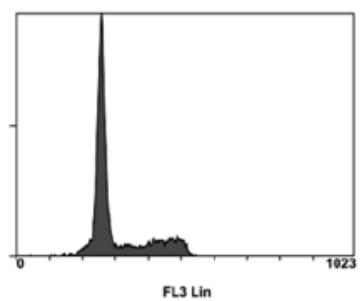

$72 \mathrm{~h}$

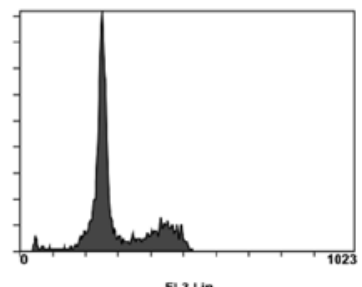

B

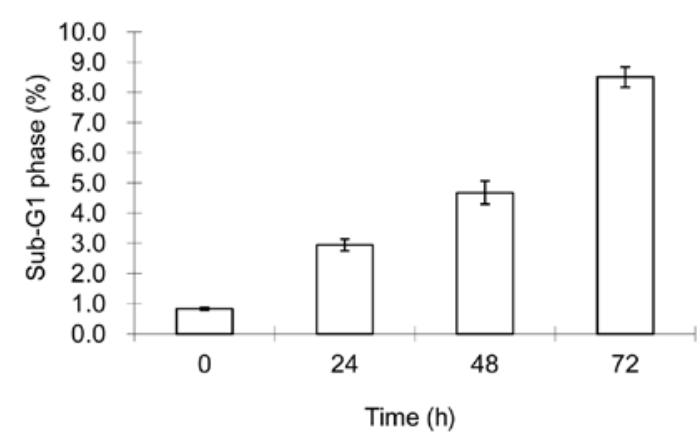

Figure 2. Cell cycle effect of Tan-IIA in BT-20 cells. The BT-20 cells were treated with Tan-IIA ( $3 \mu \mathrm{g} / \mathrm{ml})$ for different durations $(24,48$ and $72 \mathrm{~h})$, and then stained with propidium iodide. The cell cycle was determined by FACS assay as described in Materials and methods. The percentages of sub-G1 cells were $0.8,2.9,4.7$ and $8.5 \%$ at $0,24,48$ and $72 \mathrm{~h}$, respectively.

$98.83 \pm 6.21,92.14 \pm 8.06,49.5 \pm 8.35,26.32 \pm 3.63,20.52 \pm 1.49$ and $17.8 \pm 0.58 \%$, respectively, when cultured with $0.25,0.5,1$, 2, 4 and $8 \mu \mathrm{g} / \mathrm{ml}$ Tan-IIA for $48 \mathrm{~h}$. The viable cell percentages
A control

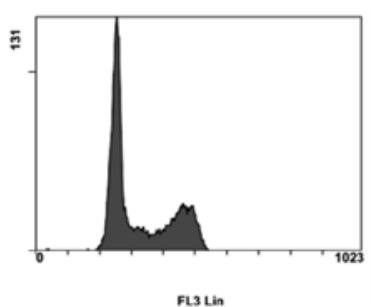

$3 \mu \mathrm{g} / \mathrm{ml}$

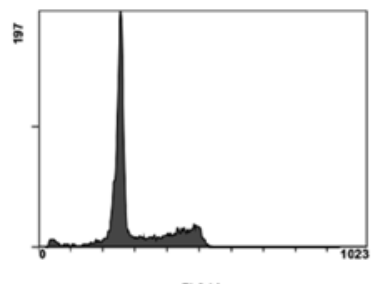

FL3 Lin

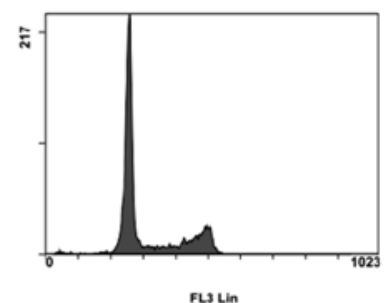

$4.5 \mu \mathrm{g} / \mathrm{ml}$

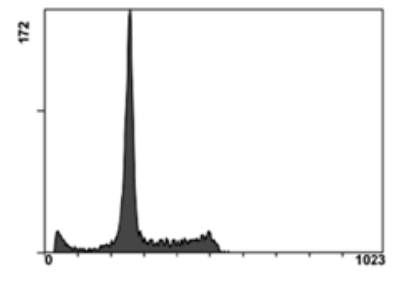

FL3Lin

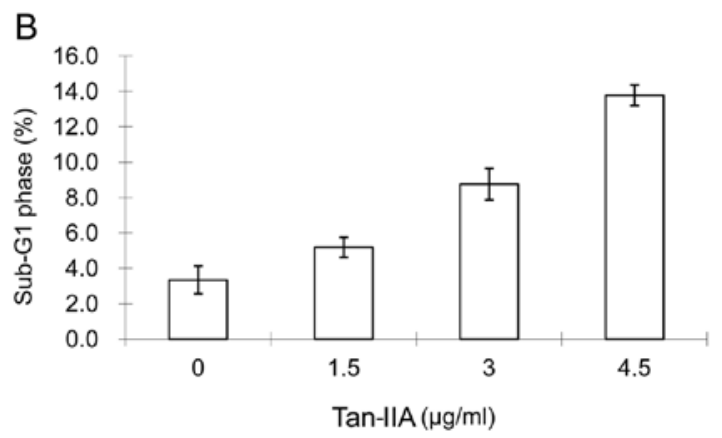

Figure 3. Cell cycle effect of Tan-II A in BT-20 cells. The BT-20 cells were treated with various concentrations of Tan-IIA $(0,1.5,3$ and $4.5 \mu \mathrm{g} / \mathrm{ml})$ for $24 \mathrm{~h}$, and then stained with propidium iodide. The cell cycle was determined by FACS assay as described in Materials and methods. The percentages of sub-G1 cells were $3.3,5.2,8.8$ and $13.8 \%$ after treatment with $0,1.5,3$ and $4.5 \mu \mathrm{g} / \mathrm{ml}$ Tan-AII, respectively.

relative to control were $79.67 \pm 3.35,61.43 \pm 3.79,34.7 \pm 1.26$, $15.11 \pm 1.67,10.78 \pm 0.89$ and $7.08 \pm 0.32 \%$, respectively, when cultured with $0.25,0.5,1,2,4$ and $8 \mu \mathrm{g} / \mathrm{ml}$ for $72 \mathrm{~h}$ (Fig. 1). The $\mathrm{IC}_{50}$ of Tan-IIA for BT-20 cells treated for different durations $(24,48$ and $72 \mathrm{~h}$ ) were $3.3,1.87$ and $0.67 \mu \mathrm{g} / \mathrm{ml}$, respectively. These results showed that Tan-IIA could inhibit BT-20 cells in a dose- and time-dependent manner (Fig. 1).

Tan-IIA induced apoptosis in BT-20 cells. The BT-20 cells were plated in 12-well plates at a density of $6 \times 10^{5}$ cells/well and then were treated with Tan-IIA $(3 \mu \mathrm{g} / \mathrm{ml})$ for different durations $(24,48$ and $72 \mathrm{~h})$. The cell cycles were analyzed by FACS. The results showed that the percentages of sub-G1 cells were $0.8,2.9,4.7$ and $8.5 \%$, respectively, when BT-20 cells were treated with Tan-IIA for 0, 24, 48 and 72 h (Fig. 2).

The BT-20 cells were plated in 12-well plates at a density of $6 \times 10^{5}$ cells/well and then were treated with various concentrations of Tan-IIA $(0,1.5,3$ and $4.5 \mu \mathrm{g} / \mathrm{ml})$ for $24 \mathrm{~h}$. The cell cycle distributions were analyzed by FACS. The results showed that the percentages of sub-G1 were 3.3, 5.2, 8.8 and $13.8 \%$, respectively, when BT-20 cells were treated with 0 , 
A

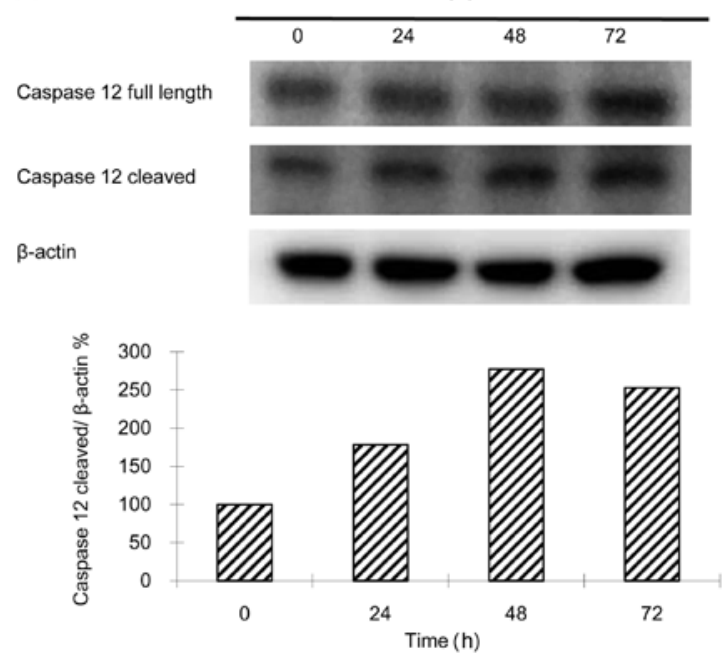

C
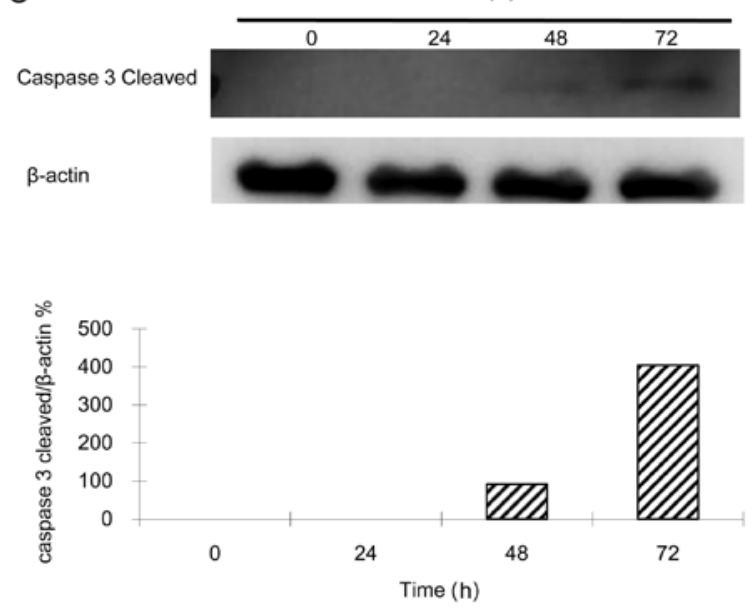

B

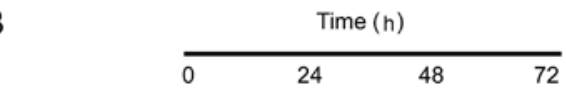

GADD153

$\beta$-actin
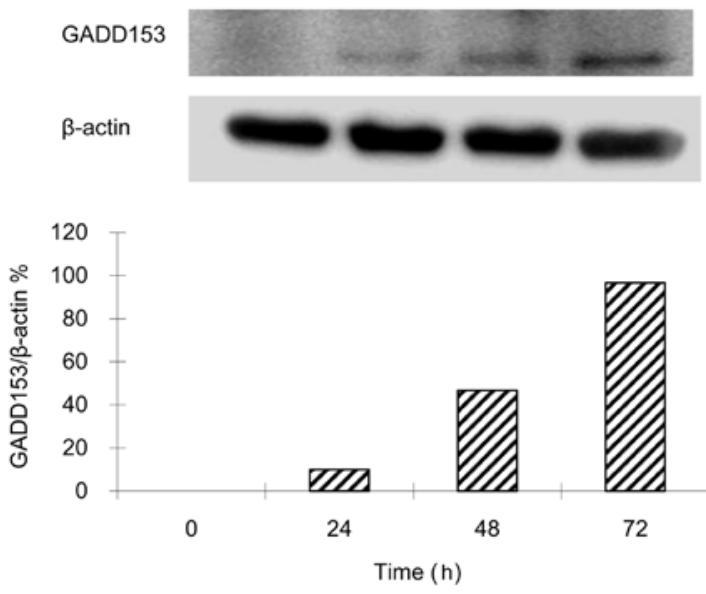

D

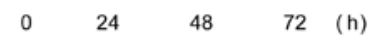

calreticulin

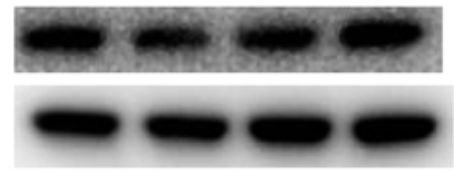

$\beta$-actin

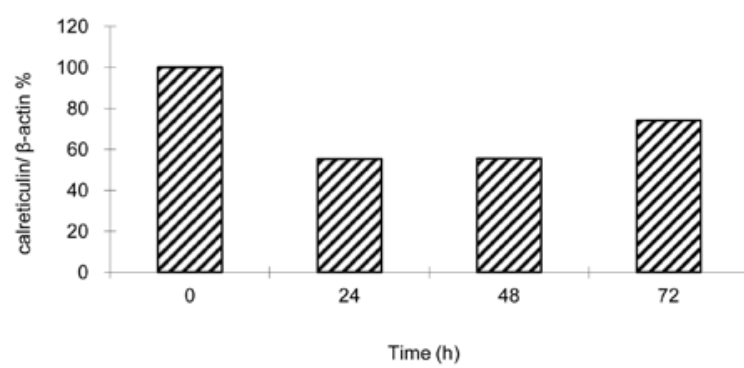

Figure 4. Protein expression of caspase 12, caspase 3, GADD153 and calreticulin in BT-20 cells. The expression levels of ER stress-associated proteins in BT-20 cells treated with Tan-IIA ( $3 \mu \mathrm{g})$ for different durations $(24,48$ and $72 \mathrm{~h})$ were measured by western blotting as described in Materials and methods. The results show that Tan-IIA increases the protein expression of (A) caspase 12, (B) GADD153 and (C) cleaved caspase- 3 but (D) decreases calreticulin expression.

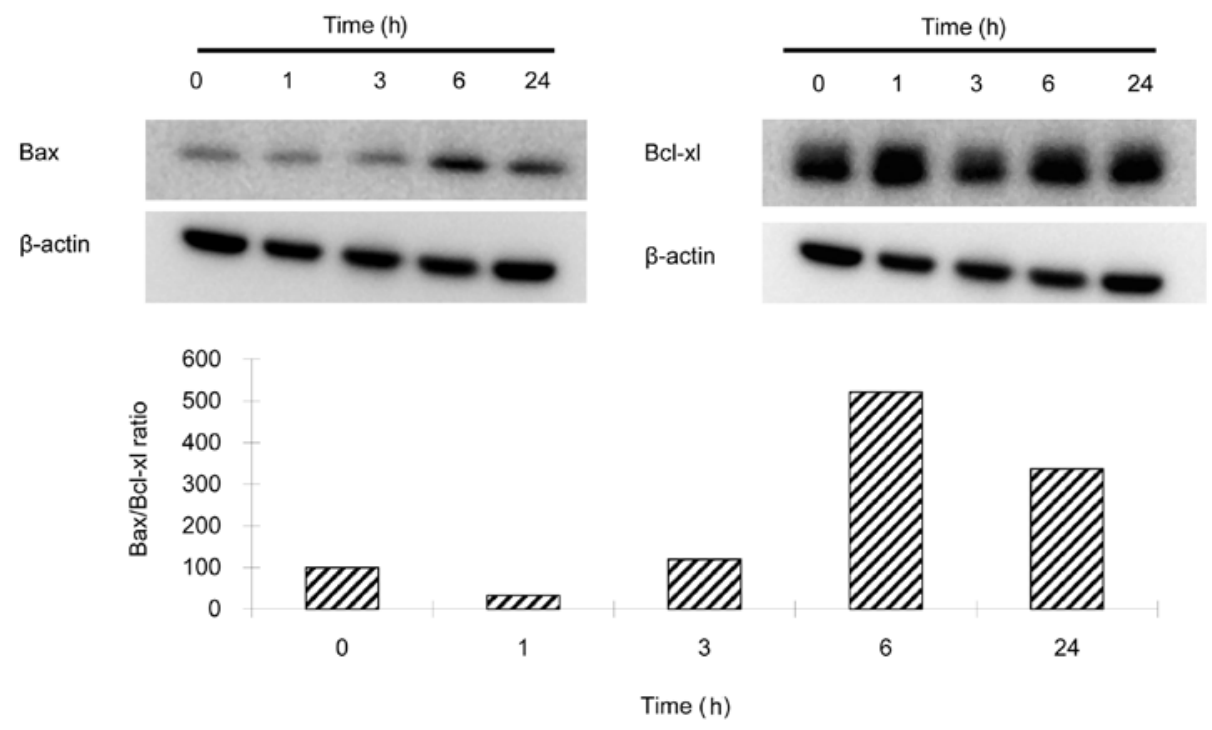

Figure 5. Protein expression of Bax, Bcl-xl and $\beta$-actin in BT-20 cells. BT-20 cells were treated with Tan-IIA ( $3 \mu \mathrm{g} / \mathrm{ml})$ for different durations (1,3,6 and $24 \mathrm{~h})$. The protein expression levels were measured by western blotting as described in Materials and methods. The results show that Tan-IIA could increase the ratio of Bax/Bcl-xl at the 6 and $24 \mathrm{~h}$ time points. 
A

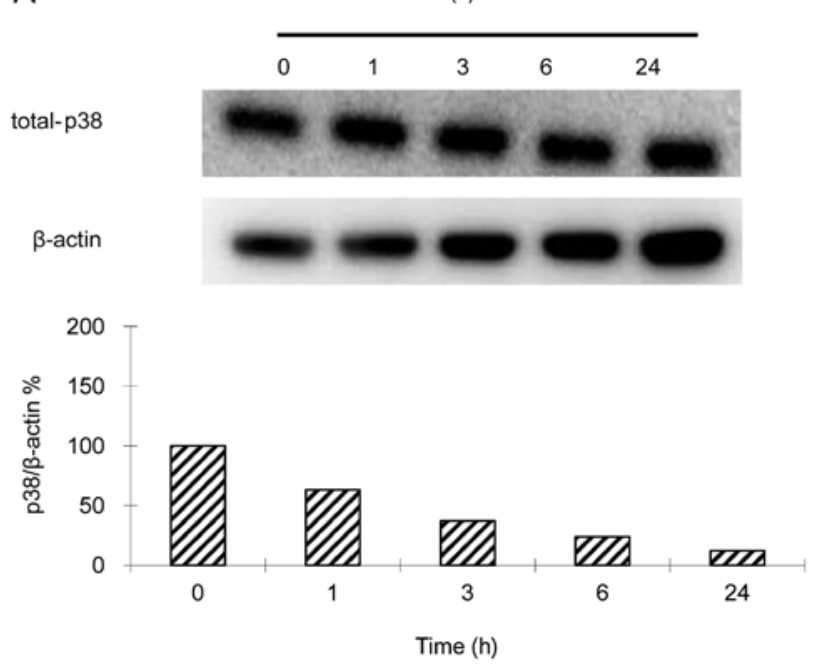

B

\begin{tabular}{lllll}
\multicolumn{4}{c}{ Time(h) } \\
\hline 0 & 1 & 3 & 6 & 24
\end{tabular}

Phospho-p38

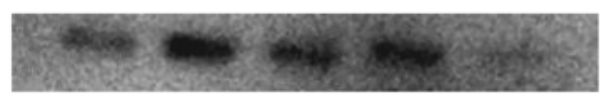

$\beta$-actin
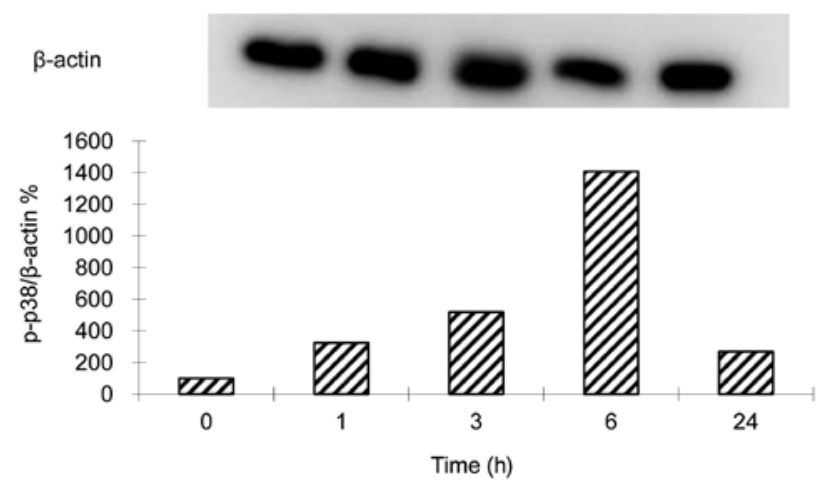

Figure 6. Protein expression of p-p38, p38 and $\beta$-actin in BT-20 cells. The expression levels of the MAPK pathway associated proteins in BT-20 cells treated with Tan-IIA $(3 \mu \mathrm{g})$ for different durations $(1,3,6$ and $24 \mathrm{~h})$ were measured by western blotting as described in Materials and methods. The results show that Tan-IIA decreases the protein expression of (A) total-p38 but (B) increases the protein expression of p-p38, especially at the $6 \mathrm{~h}$ time point.

A
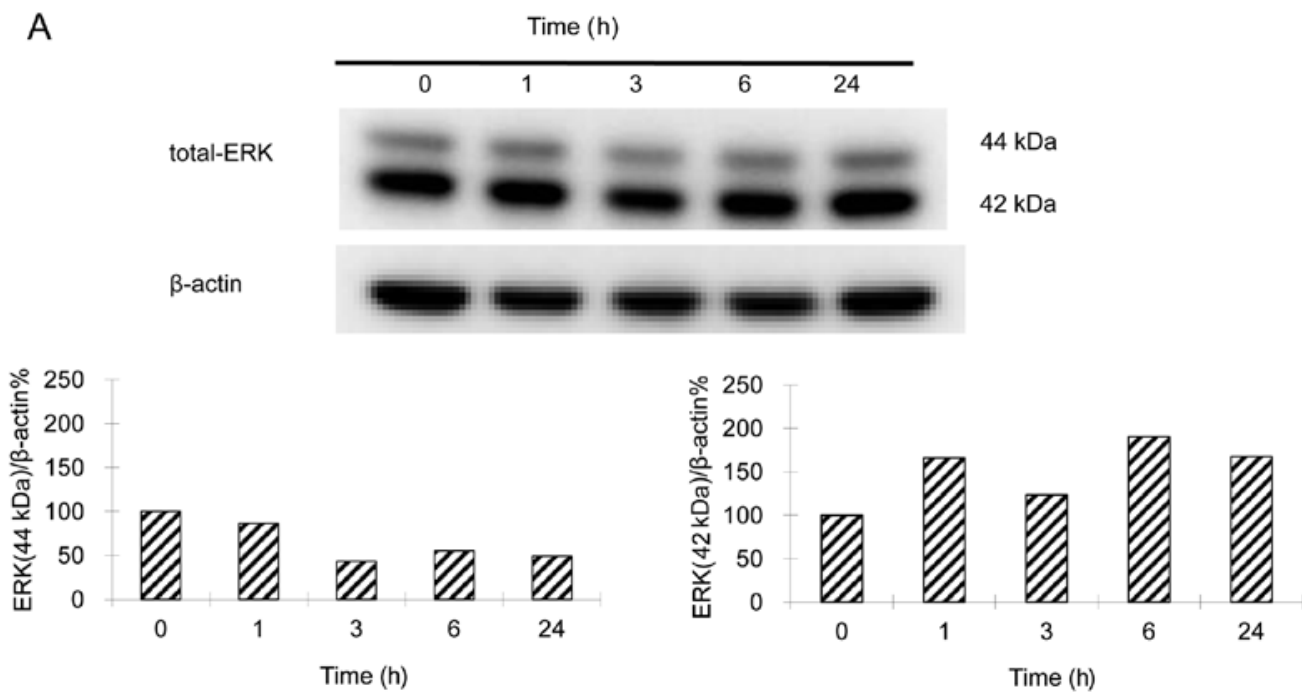

B
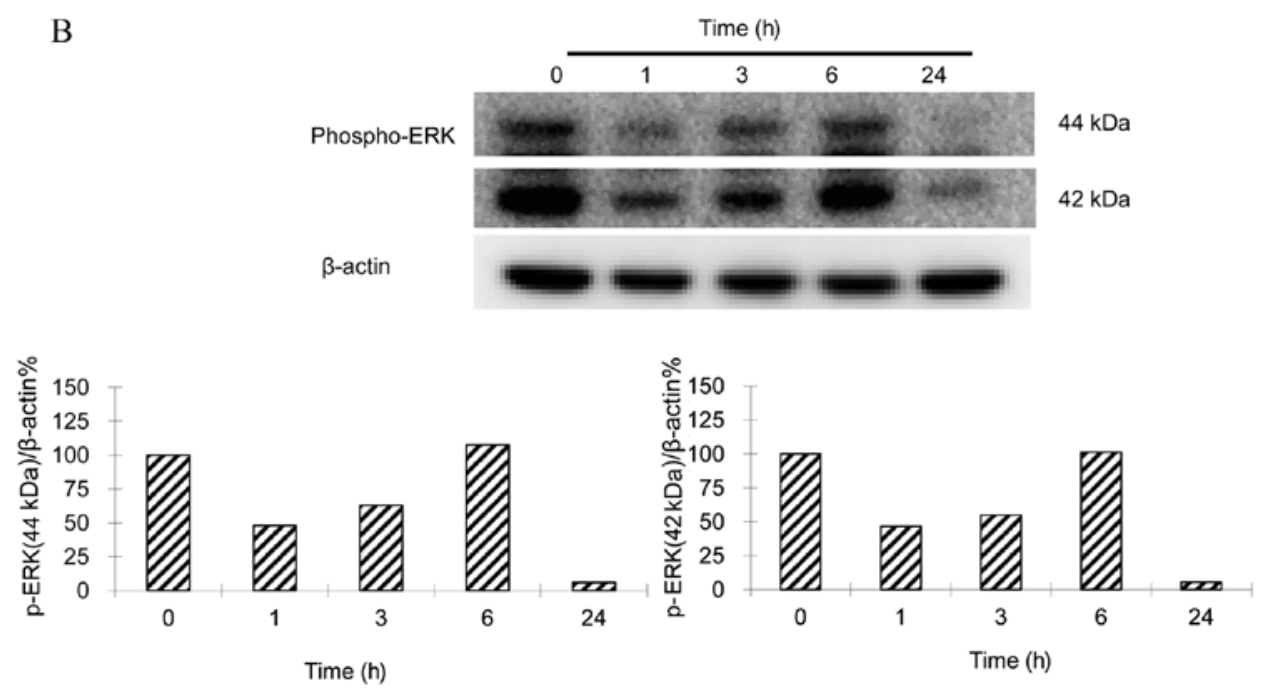

Figure 7. Protein expression of p-ERK, ERK and $\beta$-actin in BT-20 cells. The MAPK pathway associated protein expression in BT-20 cells treated with Tan-IIA $(3 \mu \mathrm{g})$ for different durations (1, 3, 6 and $24 \mathrm{~h})$ were measured by western blotting as described in Materials and methods. The results show that Tan-IIA can decrease the protein expression of (A) total-ERK ( $44 \mathrm{kDa})$ and (B) p-ERK, especially at the $24 \mathrm{~h}$ time point. 

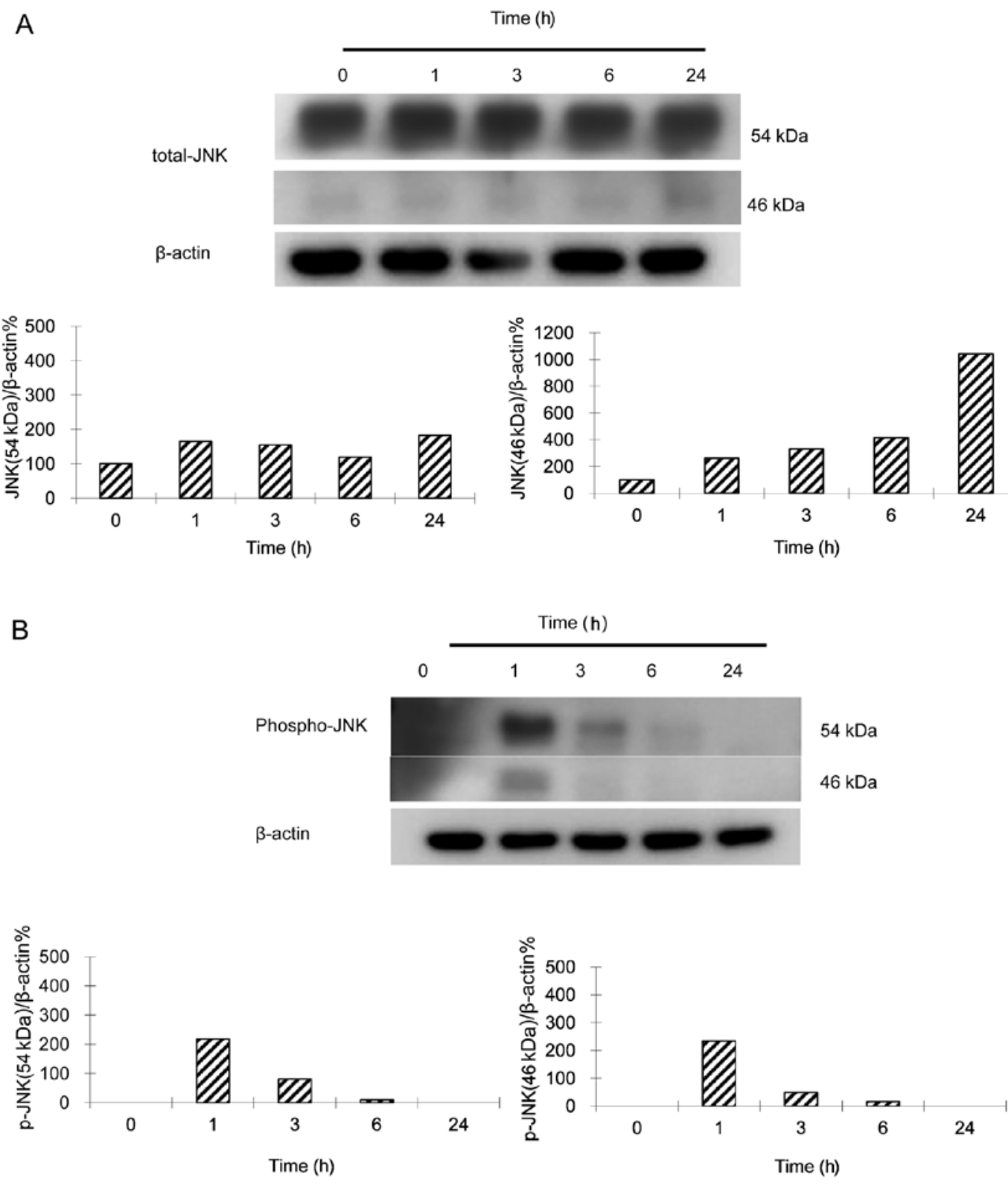

Figure 8. Protein expression of p-JNK, JNK and $\beta$-actin in BT-20 cells. The MAPK pathway associated protein expression levels in BT-20 cells treated with Tan-IIA $(3 \mu \mathrm{g})$ for different durations $(1,3,6$ and $24 \mathrm{~h})$ were measured by western blotting as described in Materials and methods. The results show that Tan-IIA increases the protein expression of total-JNK (54 and $46 \mathrm{kDa}$ ) (A) and p-JNK (54 and $46 \mathrm{kDa}$ ), especially at $1 \mathrm{~h}$ duration (B).

$1.5,3$ and $4.5 \mu \mathrm{g} / \mathrm{ml}$ Tan-IIA for $24 \mathrm{~h}$ (Fig. 3). These results showed that Tan-IIA can induce apoptosis in a time- and dosedependent manner.

The effects of Tan-IIA on the protein expression of calreticulin, caspase 12, cleaved caspase 3 and GADD153 in BT-20 cells. BT-20 cells were treated with Tan-IIA $(3 \mu \mathrm{g} / \mathrm{ml})$ for different durations $(24,48$ and $72 \mathrm{~h})$ and the proteins expression levels were evaluated by western blotting. The results showed that Tan-IIA increased the protein expression levels of caspase 12 (Fig. 4A), GADD153 (Fig. 4B) and cleaved caspase 3 (Fig. 4C), but decreased calreticulin expression (Fig. 4D). These results suggest that Tan-IIA can induce ER stress in BT-20 cells.

The effects of Tan-IIA on the protein expression of Bax, Bcl-xl, p-JNK, JNK, p-p38, p38, p-ERK and ERK in BT-20 cells.
BT-20 cells were treated with Tan-IIA ( $3 \mu \mathrm{g} / \mathrm{ml})$ for different durations (1, 3, 6 and $24 \mathrm{~h})$ and the protein expression levels were evaluated by western blotting. The results showed that Tan-IIA could increase the ratio of Bax/Bcl-xl at the 6 and $24 \mathrm{~h}$ time points (Fig. 5). The results also showed that Tan-IIA decreased the protein expression levels of total-p38 (Fig. 6A) but increased the protein expression levels of p-p38 (Fig. 6B). Tan-IIA decreased the protein expression levels of totalERK (44 kDa) (Fig. 7A) and p-ERK (Fig. 7B). Tan-IIA also increased the protein expression levels of total-JNK (54 and $46 \mathrm{kDa}$ ) (Fig. 8A) and p-JNK (54 and $46 \mathrm{kDa}$ ) (Fig. 8B).

Immunocytochemical analysis. BT-20 cells were treated with Tan-IIA $(0,3,6$ and $9 \mu \mathrm{g} / \mathrm{ml})$ for $24 \mathrm{~h}$, and then were fixed with $4 \%$ paraformaldehyde to allow for the detection of caspase 12 and caspase 3 by staining with the respective antibodies. BT-20 
A

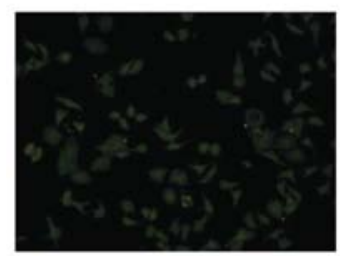

control
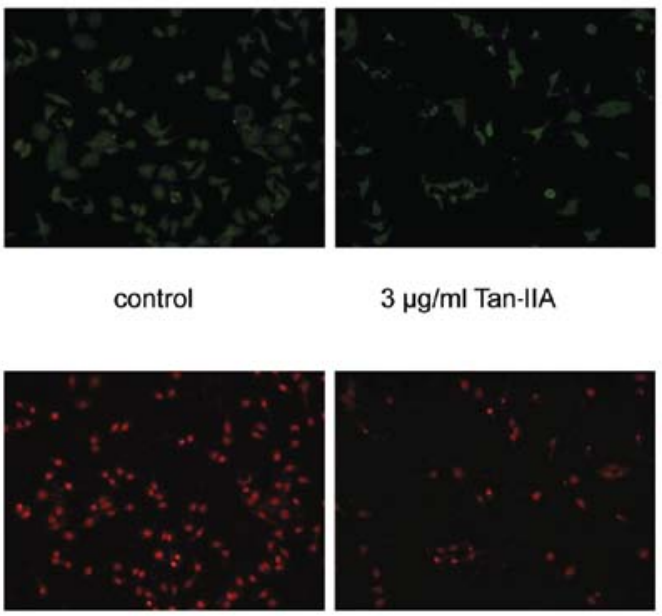

$3 \mu \mathrm{g} / \mathrm{ml}$ Tan-IIA caspase 12

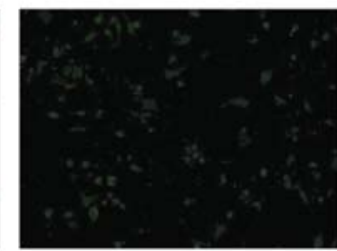

$6 \mu \mathrm{g} / \mathrm{ml}$ Tan- IIA

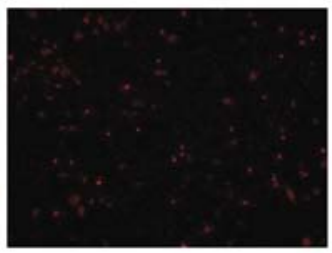

PI

B

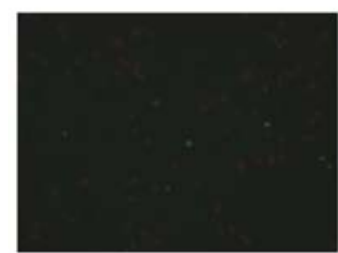

control

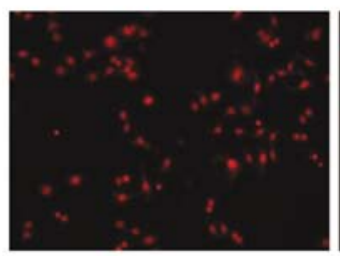

cleaved caspase 3

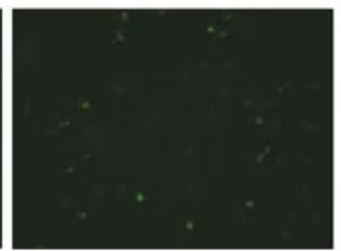

$3 \mu \mathrm{g} / \mathrm{ml}$ Tan-IIA

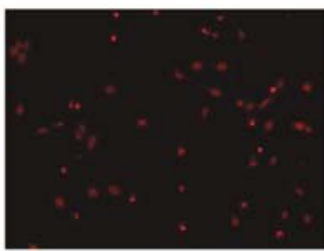

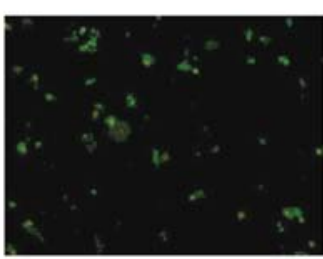

$6 \mu \mathrm{g} / \mathrm{ml}$ Tan- $\| \mathrm{A}$

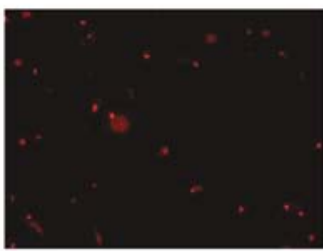

PI

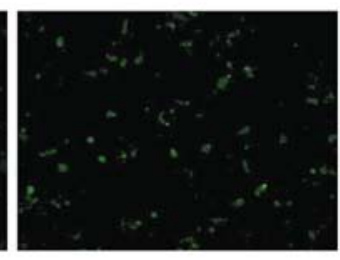

$9 \mu \mathrm{g} / \mathrm{ml}$ Tan-IIA
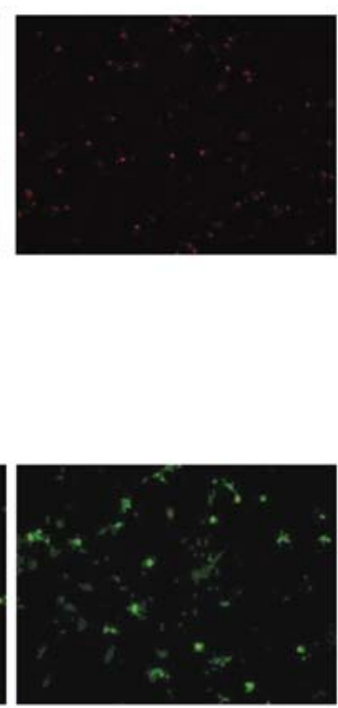

$9 \mu \mathrm{g} / \mathrm{ml}$ Tan-IIA

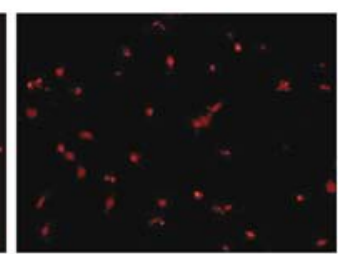

Figure 9. Immunocytochemical analysis. BT-20 cells were treated with Tan-IIA $(0,3,6$ and $9 \mu \mathrm{g} / \mathrm{ml})$ for $24 \mathrm{~h}$, and then were fixed with $4 \%$ paraformaldehyde and stained with antibodies (caspases 12 and 3). Color staining for PI was red, and for caspases 12 and 3 were green. The results showed that BT-20 cells treated with Tan-IIA had increased expression of (A) caspase 12, and (B) caspase 3 when compared to the control group.

cells treated with Tan-IIA showed increased expression of caspase 12 (Fig. 9A) and caspase 3 (Fig. 9B), and the effect was dose-dependent. These results suggest that Tan-IIA induces ER stress and apoptosis in BT-20 cells.

Effects of SB203580, PD98059 and ZVAD-FMK in BT-20 cells. BT-20 cells were pretreated with the p38 inhibitor $(50 \mu \mathrm{M}) \mathrm{SB} 203580$, the ERK inhibitor $(50 \mu \mathrm{M})$ PD98059, Cell Signaling Technology) and the caspase inhibitor $(50 \mu \mathrm{M})$ ZVAD-FMK, for $1 \mathrm{~h}$, followed by treatment with Tan-IIA ( $3 \mu \mathrm{g} / \mathrm{ml}$ ) for $24 \mathrm{~h}$. Cell viability was determined by the MTT assay. The results showed that the viable cell percentages of BT-20 cells treated with the p38 inhibitor SB203580 and with Tan-IIA significantly increased when compared to BT-20 cells treated with Tan-IIA alone. The viable cell percentages of BT-20 cells treated with the ERK inhibitor PD98059 and Tan-IIA increased significantly when compared to BT-20 cells treated with Tan-IIA alone (Fig. 10). Pretreatment of BT-20 cells with SB203580 or PD98059 decreased the cytotoxicity of Tan-IIA in BT-20 cells. These results showed that one of the molecular mechanisms for Tan-IIA to inhibit BT-20 cells may be through the MAPK pathway.

In conclusion, Tan-IIA could inhibit human breast cancer BT-20 cells in a time- and dose-dependent manner. This is in agreement with other reports $(8,10,17,18)$. It is welldocumented that activation of ER stress activates the upstream element caspase 12, followed by the upregulation of the target protein $\mathrm{C} / \mathrm{EBP}$-homologous protein (CHOP; also known as GADD153) (24). In the present study, the results showed that Tan-IIA could increase the protein expression levels of caspase 12, GADD153 and caspase 3. These results indicate that Tan-IIA could induce ER stress and apoptosis in BT-20 cells. It is well-documented that when GADD153 is upregulated Bcl-2 expression is suppressed $(25,26)$. Our results also 


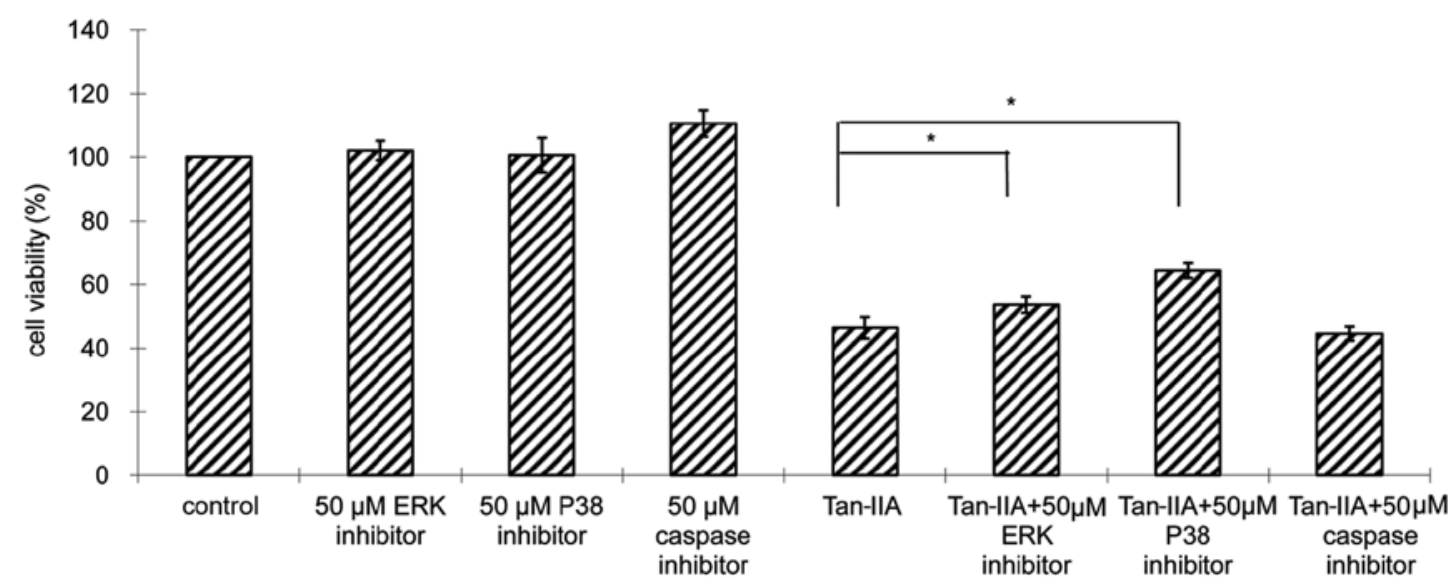

Figure 10. Effects of SB203580, PD98059 and ZVAD-FMK in BT-20 cells. BT-20 cells were pretreated with the p38 inhibitor (50 $\mu$ M) (SB203580), ERK inhibitor $(50 \mu \mathrm{M})(\mathrm{PD} 98059)$, caspase inhibitor $(50 \mu \mathrm{M})$ (ZVAD-FMK) for $1 \mathrm{~h}$, respectively, then were treated with Tan-IIA $(3 \mu \mathrm{g} / \mathrm{ml})$ for $24 \mathrm{~h}$. Cell viability was determined by the MTT assay as described in Materials and methods. The viable cell percentages of BT-20 cells treated with the p38 inhibitor, SB203580 and Tan-IIA, increased significantly when compared to BT-20 cells treated with Tan-IIA alone. The viable cell percentages of BT-20 cells treated with ERK inhibitor, PD98059 and Tan-IIA increased significantly when compared to BT-20 cells treated with Tan-IIA alone. Each point is the mean \pm SD of three experiments. ${ }^{*} \mathrm{P}<0.05$ compared to control.

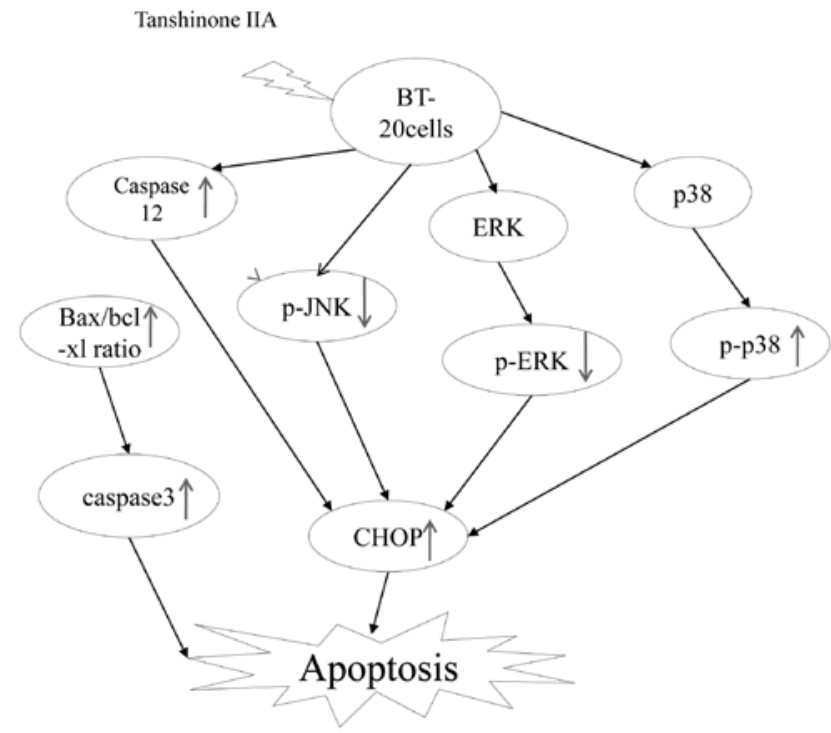

Figure 11. Proposed model for the molecular mechanisms of Tan-IIA to inhibit the proliferation of BT-20 cells through the ER stress and MAPK pathway.

showed that Tan-IIA increased the ratio of Bax/Bcl-xl. It was suggested that Tan-IIA induces ER stress to inhibit proliferation through increasing the ratio of $\mathrm{Bax} / \mathrm{Bcl}-\mathrm{xl}$ in BT-20 cells. The MAPK pathway (JNK, p38 and ERK) is one of the molecular mechanisms to regulate cancer cell activity. Phospho-p38 can induce apoptosis and phospho-ERK can inhibit apoptosis (27-29). Our results showed that Tan-IIA increased the protein expression levels of p-JNK (especially after $1 \mathrm{~h}$ ) and p-p38 (especially after $6 \mathrm{~h}$ ). Our results also showed that Tan-IIA decreased the p-ERK protein expression levels, especially at $24 \mathrm{~h}$. The proposed model of the interactions between ER stress and the MAPK pathway in BT-20 cells treated with Tan-IIA is shown in Fig. 11.

This is the first report to demonstrate that Tan-IIA inhibits human breast cancer BT-20 cells through increasing caspase 12, GADD153, p-p38, p-JNK and caspase 3 protein expression levels and by decreasing $\mathrm{p}$-ERK expression. These findings indicate that Tan-IIA has therapeutic potential in human breast cancer BT-20 cells. One of the molecular mechanisms for the Tan-IIA effects may be through inducing ER stress and the MAPK pathway to induce apoptosis and inhibit proliferation. It is necessary to perform an in vivo study to further confirm the effects of Tan-IIA observed in the in vitro breast cancer cell line.

\section{Acknowledgements}

This study was supported by grant 100-CCH-IRP-96 from the Research Section of the Changhua Christian Hospital, Changhua, Taiwan, R.O.C.

\section{References}

1. Lin TJ: Antioxidation mechanism of schizandrin and tanshinonatic acid $A$ and their effects on the protection of cardio-toxic action of adriamycin. Sheng Li Ke Xue Jin Zhan 22: 342-345, 1991 (In Chinese).

2. Wang AM, Sha SH, Lesniak W and Schacht J: Tanshinone (Salviae miltiorrhizae extract) preparations attenuate aminoglycoside-induced free radical formation in vitro and ototoxicity in vivo. Antimicrob Agents Chemother 47: 1836-1841, 2003.

3. Lin R, Wang WR, Liu JT, Yang GD and Han CJ: Protective effect of tanshinone IIA on human umbilical vein endothelial cell injured by hydrogen peroxide and its mechanism. J Ethnopharmacol 108: 217-222, 2006.

4. Liang Y, Yang YM and Yuan SL: Studies on Pharmic mechanism and clinic application of tanshinone. Traditional Herbal Drugs 31: 304-306, 2000

5. Jang SI, Kim HJ, Kim YJ, Jeong SI and You YO: Tanshinone IIA inhibits LPS-induced NF-kappaB activation in RAW 264.7 cells: possible involvement of the NIK-IKK, ERK1/2, p38 and JNK pathways. Eur J Pharmacol 542: 1-7, 2006.

6. Li W, Li J, Ashok M, Wu R, Chen D, Yang L, et al: A cardiovascular drug rescues mice from lethal sepsis by selectively attenuating a late-acting proinflammatory mediator, high mobility group box 1. J Immunol 78: 3856-3864, 2007.

7. Yuan SL, Wei YQ, Wang XJ, Xiao F, Li SF and Zhang J: Growth inhibition and apoptosis induction of tanshinone II-A on human hepatocellular carcinoma cells. World J Gastroenterol 10: 2024-2028, 2004. 
8. Wang X, Wei Y, Yuan S, Liu G, Lu Y, Zhang J, et al: Potential anticancer activity of tanshinone IIA against human breast cancer. Int J Cancer 116: 799-807, 2005.

9. Liu JJ, Lin DJ, Liu PQ, Huang M, Li XD, Huang RW: Induction of apoptosis and inhibition of cell adhesive and invasive effects by tanshinone IIA in acute promyelocytic leukemia cells in vitro. J Biomed Sci 13: 813-823, 2006.

10. Su CC and Lin YH: Tanshinone IIA inhibits human breast cancer cells through increased Bax to Bcl-xL ratios. Int J Mol Med 22: 357-361, 2008.

11. Su CC and Lin YH: Tanshinone IIA downregulates the protein expression of ErbB-2 and upregulates TNF- $\alpha$ in colon cancer cells in vitro and in vivo. Int J Mol Med 22: 847-851, 2008

12. Su CC, Chen GW, Kang JC and Chan MH: Growth inhibition and apoptosis induction by tanshinone IIA in human colon adenocarcinoma cells. Planta Med 74: 1357-1362, 2008.

13. Cheng CY and Su CC: Tanshinone IIA may inhibit the growth of small cell lung cancer H146 cells by upregulating the Bax/ $\mathrm{Bcl}-2$ ratio and decreasing mitochondrial membrane potential. Mol Med Rep 3: 645-650, 2010.

14. Chiu TL and Su CC: Tanshinone IIA induces apoptosis in human lung cancer A549 cells through the induction of reactive oxygen species and decreasing the mitochondrial membrane potential. Int J Mol Med 25: 231-236, 2010.

15. Cheng CY and Su CC: Tanshinone IIA inhibits Hep-J5 cells by increasing calreticulin, caspase 12 and GADD153 protein expression. Int J Mol Med 26: 379-385, 2010.

16. Jemal A, Bray F, Center MM, Ferlay J, Ward E and Forman D Global cancer statistics. CA Cancer J Clin 61: 1-22, 2011.

17. Lu Q, Zhang P, Zhang X and Chen J: Experimental study of the anti-cancer mechanism of tanshinone IIA against human breast cancer. Int J Mol Med 24: 773-780, 2009.

18. Zhang PR and Lü Q: A study on anticancer activity of tanshinone IIA against human breast cancer. Sichuan Da Xue Xue Bao Yi Xue Ban Mar 40: 245-249, 2009 (In Chinese).

19. Zhang X, Zhang PR, Chen J and Lü Q: A study on the effect of Tanshinone II A against human breast cancer in vivo. Sichuan Da Xue Xue Bao Yi Xue Ban 41: 62-67, 2010 (In Chinese).
20. Chen YL, Jian MH, Lin CC, Kang JC, Chen SP, Lin PC, Hung PJ, Chen JR, Chang WL, Lin SZ and Harn HJ: The induction of orphan nuclear receptor Nur77 expression by n-butylenephthalide as pharmaceuticals on hepatocellular carcinoma cell therapy. Mol Pharmacol 74: 1046-1058, 2008.

21. Su CC, Chen GW and Lin JG: Growth inhibition and apoptosis induction by tanshinone I in human colon cancer Colo 205 cells. Int J Mol Med 22: 613-618, 2008.

22. Chan SE, Lai HW, Su CC, Kuo SJ, Chien SY, Lin HY and Chen DR: Effect of supplementation of tanshinone IIA and sodium tanshinone IIA sulfonate on the anticancer effect of epirubicin: an in vitro study. Evid Based Complement Alternat Med 2011: 841564, 2011.

23. Mossman T: Rapid colorimetric assay for cellular growth and survival: application to proliferation and cytotoxicity assays. J Immunol Methods 65: 55-63, 1983.

24. Ma Y and Hendershot LM: The role of the unfolded protein response in tumour development: friend or foe? Nat Rev Cancer 4: 966-977, 2004.

25. Kim R, Emi M, Tanabe K and Murakami S: Role of the unfolded protein response in cell death. Apoptosis 11: 5-13, 2006.

26. Rasheva VI and Domingos PM: Cellular responses to endoplasmic reticulum stress and apoptosis. Apoptosis 14: 996-1007, 2009.

27. Kim SM, Park HS, Jun DY, Woo HJ, Woo MH, Yang CH and Kim YH: Mollugin induces apoptosis in human Jurkat T cells through endoplasmic reticulum stress-mediated activation of JNK and caspase- 12 and subsequent activation of mitochondriadependent caspase cascade regulated by Bcl-xL. Toxicol Appl Pharmacol 241: 210-220, 2009.

28. Wagner EF and Nebreda AR: Signal integration by JNK and p38 MAPK pathways in cancer development. Nat Rev Cancer 9: 537-549, 2009.

29. Jin UH, Suh SJ, Chang HW, Son JK, Lee SH, Son KH, Chang YC and Kim CH: Tanshinone IIA from Salvia miltiorrhiza BUNGE inhibits human aortic smooth muscle cell migration and MMP-9 activity through AKT signalingpathway. J Cell Biochem 104: $15-26,2008$ 